\title{
Correction
}

\section{Correction: Effects of cyclophosphamide on pulmonary function in patients with scleroderma and interstitial lung disease: a systematic review and meta-analysis of randomized controlled trials and observational prospective cohort studies}

\author{
Carlotta Nannini ${ }^{1}$, Colin P West ${ }^{2,3}$, Patricia J Erwin ${ }^{4}$ and Eric L Matteson ${ }^{1}$ \\ 1Division of Rheumatology, Mayo Clinic College of Medicine, 200 First Street SW, Rochester, MN 55905, USA \\ 2Division of General Internal Medicine, Mayo Clinic College of Medicine, 200 First Street SW, Rochester, MN 55905, USA \\ ${ }^{3}$ Division of Biostatistics, Mayo Clinic College of Medicine, 200 First Street SW, Rochester, MN 55905, USA \\ ${ }^{4}$ Medical Library, Mayo Clinic College of Medicine, 200 First Street SW, Rochester, MN 55905, USA
}

Corresponding author: Carlotta Nannini, nannini.carlotta@mayo.edu

Published: 30 April 2009

Arthritis Research \& Therapy 2009, 11:408 (doi:10.1186/ar2679)

This article is online at http://arthritis-research.com/content/11/2/408

(C) 2009 BioMed Central Ltd

See related research by Nannini et al., http://arthritis-research.com/content/10/5/R124

It has been brought to our attention that Figure $2 \mathrm{~b}$ in our recently published paper [1] contains an error. Specifically, we inadvertently entered -6.4 rather than +6.4 for the Nadaskevich paper [2] reported in Figure 2b. Recalculation of the summary estimate for diffusing lung capacity of carbon monoxide (DLCO) in this figure revealed a summary mean difference of 3.74 , with $95 \%$ confidence interval (0.09 to 7.40). This effect is now statistically significant, although the overall conclusion of our meta-analysis, that cyclophosphamide treatment did not result in clinically significant improvement of pulmonary function, is unchanged by this recalculation, as the improvement remains less than the predefined criterion of $10 \%$. The corrected figure $2 b$ is given here as Figure 1.

\section{References}

1. Nannini C, West CP, Erwin PJ, Matteson EL: Effects of cyclophosphamide on pulmonary function in patients with scleroderma and interstitial lung disease: a systematic review and meta-analysis of randomized controlled trials and observational prospective cohort studies. Arthritis Res Ther 2008, 10:R124.

2. Nadashkevich $\mathrm{O}$, Davis $\mathrm{P}$, Fritzler M, Kovalenko W: A randomized unblinded trial of cyclophosphamide versus azathioprine in the treatment of systemic sclerosis. Clin Rheumatol 2006, 25:205-212.

Figure 1

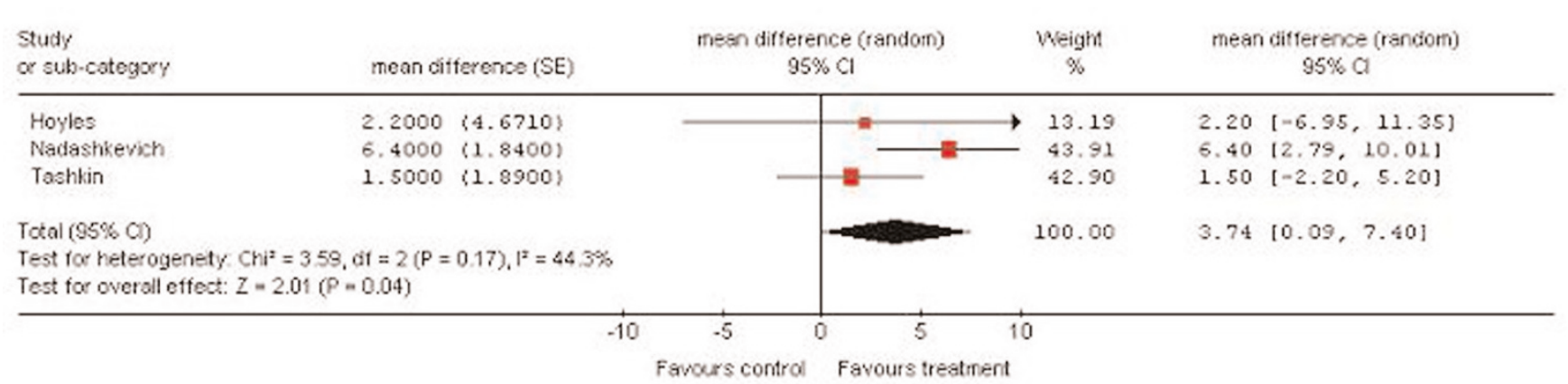

Forest plot of the overall meta-analysis result in the randomized clinical trials. Comparison of the diffusing capacity for carbon monoxide (DLCO) at 12 months for patients with scleroderma lung disease treated with cyclophosphamide versus a control group. See Table 2 [1] for study details. $\mathrm{RCT}$, randomized clinical trial; SE, standard error; Cl, confidence interval; Chi2, chi-squared; df, degree of freedom; I2, I-squared; Z, Z value; Mean difference, weighted mean difference; Random, random-effects. 